\title{
Informed consent: A study of patients with life-threatening illnesses
}

\author{
Montserrat Busquets ${ }^{1}$, Jordi Caïs ${ }^{2}$
}

1. Department of Fundamental Care and Medical-Surgical Nursing, University of Barcelona

2. Department of Sociology and Organizational Analysis, University of Barcelona

\begin{abstract}
:
Background: The relationship between healthcare professionals and patients in the Spanish health sector has undergone dramatic change. One aspect of this is that the use of informed consent has become a key factor in the delivery of adequate healthcare. But although a certain period of time has already passed since informed consent started to be used, in Spain there is still doubt about how adequately informed consent is being used.
\end{abstract}

Objectives: a)To look at how patients understand the notion and purpose of informed consent, and b) how the informed consent is applied -the way patients receive such information affects their level of participation and decision making during the time they receive medical care.

Methodology: We use interpretative description of interviews with patients. We developed guiding questions for the interviews with patients in two preliminary and exploratory focus groups. Then we carried out 20 personal open-ended interviews with 20 purposive selected patients with illnesses that had a serious impact on their lives

Results: The findings show that while patients agreed that their consent should be necessary for health professionals to be able to intervene, they had serious difficulty obtaining and then understanding information offered to them at the moment when they were being asked to sign informed consent documents. The participants were critical of the consent documents, which they considered were treated as merely a formality and even some of them had felt coerced to sign.

Discussion: Participants confirmed that the informed consent documents that they signed did not meet their ethical objectives. Their perception of the purpose of consent indicates that informed consent document may still be largely understood as a formality rather an ethical obligation. The results suggest that there is an important need for health professionals to receive training in health ethics in this area of practice.

Key words: informed consent, autonomy, information, nursing intervention, paternalism 


\section{Introduction}

Healthcare providers in the Spanish sector need to understand the complexity and importance of informed consent. For the last twenty-five years, informed consent has been a key factor in the development of good medical and nursing practice in both clinical care and clinical research with human subjects. ${ }^{1}$ In order to meet their responsibilities, physicians and nurses must be sure that patients receive the information and assistance that most clearly explains their medical condition. This information must help the patient make a reasoned decision about whether to consent to a course of treatment or intervention and receive the care this requires. ${ }^{2}$ Healthcare providers must therefore understand that informed consent is closely linked to the ethical principle of respecting patient autonomy.

"Patient autonomy" is the patient's right to make choices about medical care without healthcare providers trying to influence this decision. ${ }^{3}$ Patient participation in decisions about care has evolved over the years from paternalistic and hierarchical approaches centered around healing illness, towards more horizontal approaches, where patients are assuming a more active role in their own care. ${ }^{1}$ This is especially true of the Spanish system, which was once especially paternalistic and obliged the patient to play a secondary, obedient and passive role. A comparative study by Coultner and Jenkinson shows the results of a telephone survey with random samples in Germany, Italy, Poland, Slovenia, Spain, Sweden, Switzerland and the UK, about the extent to which patients felt they had been involved as much as they wanted in decisions about their care. Interestingly, more people in Spain (29\%), Poland (16\%) and Slovenia (13\%) said doctors never involved them in decisions about their care, whereas the proportion reporting no involvement in the other countries was fewer than $10 \%{ }^{4}$

The application of informed consent in the Spanish health sector has helped patients assume a more participative role in the care process, enabling patient and professional to share their impressions and knowledge to find the best response to the patient's individual circumstances and medical condition. ${ }^{5}$ The aim of this study is twofold: it looks at how patients understand the notion and the purpose of informed consent, and how the informed consent is applied. Application of informed consent is relevant 
because the way patients receive such information affects their level of participation and decision making during the time they receive medical care.

\section{Theoretical principles}

Informed consent is a basic tool for consolidating patient autonomy. In order to exercise this autonomy patients need information on the nature of their condition, the choices they may have in terms of courses of treatment, and the risks and benefits of the interventions proposed to them and for which they need informed consent. ${ }^{6}$ But at the same time patient autonomy also depends on the patient's own capacity to make reasoned decisions unswayed by external pressure. In accordance with the principles of good professional practice, health professionals need to provide patients with whatever medical information will help them reorganize their lives to better negotiate their illness. They therefore need communicative skills that will help patients understand their situation and that are attuned to the patient's particular fragility and vulnerability as an ill person. ${ }^{7}$ As Fry and Johnstone observe, above all else consent means patients exercising their will to decide and understanding the information they receive and are helped to understand, and is in no way the result of coercion. ${ }^{8}$

The legal premise by which consent is recognized is the observance of people's personal right to individual freedom. ${ }^{9}$ In healthcare, this freedom is understood as the 'right to know', meaning the right to have access to information that can enable a person to make decisions that accept or reject the health professional's proposal. The law establishes this by stipulating that professional intervention may only come after informed consent has been given, either by the patient or the patient's representative. ${ }^{10}$ The legal requirement for consent dates back to the 1960s in the US, to the declaration of the Patients' Charter and the publication of the Belmont Report. ${ }^{11}$ The Council of Europe established its own instrument in 1976 and in 1997, in accordance with the Report, this was ratified in the Oviedo Convention. ${ }^{12}$ The result was that first, the EU member states have created standards regulating good professional practice and laws determining how consent processes should be implemented and that second, at 
international, national and regional levels, professional codes of ethics have also been reformulated. ${ }^{13} 1415$

In Spain, informed consent became legally required in 1986 with the General Law on Health (Article 10), which specified the rights of health service users. ${ }^{16}$ Legislation on the issue was passed in Catalonia in $2000^{17}$ and in Spain, the Patient Autonomy Act was passed in 2002. ${ }^{18}$ Both laws required that all medical interventions should be preceded by the patient's informed consent or, when he or she was declared legally incompetent, the informed consent of the patient's legal representative. Waiver of this requirement could only be applied in emergencies when neither the patient nor the legal representative could give consent, or in the case of third-party damages. In line with this, in 2003 the Committee on Bioethics of Catalonia (CBC) published a series of good clinical practice guidelines to encourage health professionals to offer patients comprehensive medical information, help them understand this information and ensure they were in a position to accept or reject the proposal being made. ${ }^{19}$

Although a certain period of time has already passed, however, there are still doubts in the Spanish health sector about how adequately informed consent is being applied. This is because of the paternalistic attitude that continues to dominate health professionals' relationships with their patients and because respecting patient autonomy has become focused on the moment when consent documents need to be signed and the information that is offered to obtain this signature. ${ }^{20}$ It is true that health professionals and institutions have sought to make adequate consent documents available to their patients and that they perceive the application of informed consent to be measure of care quality. But signing such documents and even accepting a professional proposal are not in themselves considered to be guarantees that patients have exercised their right to autonomy; patients need to have access to much more information about their health condition in order to understand the information they need to sign a consent document. In 1996 Cahill had already found that the degree of patients' participation in their own care was closely related to the quality of their relationship with their physicians and nurses. ${ }^{21}$ Patients' autonomous participation depended on their interaction with healthcare providers, the circumstances under which this interaction took place and how 
effectively patients could build their sense of autonomy during the time they received care. ${ }^{22}$ Because of this, to understand how the application of informed consent affects patient autonomy it is essential to see the situation from the patient's point of view and consider his or her experience of the process of receiving information during the health care process.

\section{Methods}

We use interpretative description of interviews with patients. ${ }^{23} 24$ This technique recognizes that experiences of health and illness comprise complex interactions between psychosocial and biological events, and it is an excellent tool to help us understand how patients understand the notion and the purpose of informed consent and how the informed consent is applied. This knowledge allows for the generation of new ideas and can inform clinical reasoning and innovative practices of care.

\section{Recruitment and sampling}

We developed guiding questions for interviews with patients in two preliminary and exploratory focus groups with five patients in each group, who highlighted issues about their experience of receiving information about their illness and how their healthcare professionals had managed the process by which informed consent was given. These issues in conjunction with a critical review of the literature guided the one-on-one interviews with study participants. The participants for the two preliminary focus groups were contacted by the authors of the article with the help of the directors of the two Barcelona-based patient support associations: Grup Àgata (for patients with breast cancer) and the Catalan Association for Assistance in Cardiology. The preliminary focus groups were conducted by the two authors of the article.

The central part of the study consisted of 20 one-on-one interviews with 20 purposive selected patients with illnesses that had a serious impact on their lives: 10 women who had had breast cancer for more than one year and 10 men who had experienced more 
than one year of coronary artery disease, either in the form of angina or myocardial infarction. The selection criteria was to be a patient, older than 18 , clinically stable, with more than one year of evolution since their illness was diagnosed -for which they have gone through several experiences of informed consent. We have excluded those patients who, during the period when the study was carried out, have required new hospitalization. The reason why we chose 10 women who had had breast cancer, which is an almost exclusively female illness, and 10 men with coronary artery disease, is that we initially thought to control for variables of gender and kind of illness; however, these variables did not appear as relevant in the analysis.

Using purposive sampling the patients to be interviewed individually were contacted and recruited by the nursing team responsible for research at Bellvitge University Hospital in Barcelona, and the two Directors of two Barcelona-based patient support associations: Grup Àgata (for patients with breast cancer) and the Catalan Association for Assistance in Cardiology. Names of the patients who were interested in participating were given to the interviewers who contacted them to send them written information about the study, to obtain informed consent and set up an interview time. Interviews were conducted at a time and location of a patients' choice (the most common locations were the interviewee's home or at the headquarters of one of the two patient support associations).

\section{Data collection and analysis}

Personal open ended interviews explored participants' experiences through discussions about: a) how patients understand the notion and the purpose of informed consent and b) how the informed consent is applied - the way patients receive the information affects their level of participation and decision making during the time they receive medical care. Typically the interviews lasted 45-60 minutes. Each interview was conducted in the interviewee's native language, either Catalan or Spanish. The two interviewers were experienced qualitative interviewers with no prior relationship to the participants. All interviews were transcribed and validated against the recorder material by the interviewer. Validation of transcripts for authenticity was facilitated by returning 
the transcripts to participants to read. ${ }^{25}$ Excerpts from transcripts were not only used to preserve the uniqueness of participant responses but also permitted an understanding of the phenomena of interest. ${ }^{26} \mathrm{We}$ used inductive analysis to examine the experience of people with health problems who had given their informed consent on one or more than one occasion while receiving medical treatment. We identified in the transcribed text the themes and statements that highlighted the patients' experiences and their perceived meaning of informed consent. This helped us to find answers to the two main questions of the study: how patients understand the notion and the purpose of informed consent and how the informed consent is applied.

\section{Ethical considerations}

The participants were recruited after the research team had applied for permission from each institution involved in the study and their respective ethical committees. Before they agreed to be in the survey, all the participants had been informed of the overall objectives of the study and the procedures that would be followed. The researchers then requested their voluntary participation, clarifying that the survey would not in any way be related to the patients' treatment and care and that they could withdraw at any moment they wished without penalty or repercussions. The individual interviews and focus groups were conducted with the participants' verbal and written consent. Nobody chose to withdraw. Anonymity was also guaranteed in the transcripts and texts of the interviews and group sessions. Finally, each participant received both by postal mail and by e-mail the transcript of their interview so that they could revise this as they saw fit, changing or removing content. No requests to change or remove content were made.

\section{Results}

The purpose of informed consent

The participants understood the purpose of informed consent in four different ways. They either thought that (a) it granted the health professional permission to prescribe a treatment or a perform a test, (b) it gave the health professional the power to do 
whatever he or she considered appropriate, (c) it gave the health professional legal protection in case something went wrong afterwards or (d) it was merely a formality.

Participants understood that the purpose of informed consent was to give health professionals permission to go further in a course of treatment. The two following interview excerpts exemplify this idea:

“The way I see it, if you don't give them your consent they can't do anything to your body."

"It means I agree; I've signed lots of these forms because I've had lots of operations.

Giving your consent means them telling you what they're going to do and you agreeing to let them."

They felt that signing the document was a way to give the health professional free reign to do what he or she wanted.

"They ask you for your consent so they can do whatever they want, because that's what they say in the document and that's it. And then you sign it."

"According to what they told me it's so that I give them permission to do whatever they need to because otherwise they can't do their work."

The interviewed patients understood that informed consent was applied in order to allow health professionals to work without the risk of being legally accountable. The three following interview excerpts reflect that way of understanding informed consent:

“'I've got to cover my back,' the doctor told me. 'We're going to try and save your breast but if it gets more complicated or something goes wrong you could take me to court'."

"Yes, it's a piece of paper that says that if I die it won't be their fault. In other words if I die they won't go to prison or anything. I'm laughing about it now but that's the truth."

"They do it in case something happens to you because they have to be realistic. It's so you can't complain afterwards. That's why the information is sometimes a little bureaucratic." 
They also think that signing the consent document is an obligatory procedure if they want to receive the treatment. They understand it as an administrative formality. One woman who signed three informed consents during the course of her treatment gave the following explanation for why she understood informed consent to be merely a formality.
"They gave me the first form a few hours before the operation. Then I signed another one for the radiotherapy, after they took my data. But not for the chemotherapy: they didn't give me any choice for that, they just said 'Sign'. Another time I remember they said 'We're going to give you a shot and you have to sign this. It's a liquid that'll help you get better'."

In the following interview excerpt a participant described and observed that the health professionals who asked him to sign gave little importance to whether he had understood the content.

"They tell you to sign the paper, that's what they always do. 'We're going to operate on you,' they say, 'so sign here'. And that's that. And my answer is 'Yeah, like sign my death sentence, right? Because there's a bunch of words here I'm not reading because you won't give me the time, because you want me to sign and be done with it.' Nobody explained anything to me."

This participant admitted that he signed the informed consent document without reading it first.

"You may think this sounds stupid but no, I didn't read it. They told me I had to sign so I did, but I didn't actually read what it was."

Participants even felt that some sort of power relationship was used, as we see in this excerpt:

“They try not to make your signature look important because they don't want you to know more than they do."

These two participants reported that they were afraid the health professional would refuse to treat them if they refused to give their consent, which gave them the feeling they were being coerced to sign. 
"Sure, the patient has the right to say no. It's your right to say no and choose not to pay any attention to what your doctor says; but then they just send you home. The fact is, when you're ill it's very difficult to say 'I won't sign this' unless they actually give you some kind of alternative."

“They don't tell you what you're going to sign. At least in my case, they always say 'this is what you have to sign so that we can run the test."

Another important factor was the document design. Participants reported that the format of the document often made comprehension more difficult and that it was difficult to read the document to the end because the register was too technical or professionallyoriented. The following explanations offered by two participants interviewed are good examples:

"I read parts of it but it was like those insurance policies: the fine print is impossible to understand. My daughters didn't read it all either."

"I ploughed through all of it and then signed. The problem is, you can't understand what they're saying. They use these words you've never heard of. And then they make it look like just because you've been given a paper means you understood everything. But when you sign it you know that nothing's going to happen: they don't say or explain anything else."

\section{How informed consent was applied}

From the interviews it appears that, on the one hand, the patients refuse paternalistic attitudes and want health professionals to keep them informed. It is also important for patients to establish a relationship with health professionals based on trust. They even accept to give their consent without having all the information they might be entitled to if they trust health service professionals. However, on the other hand, the interviews show that the patients' wishes of being informed are not fulfilled, as the participants reported being given information that seemed to be geared to obtaining their consent but contained little or no explanation about the treatment or intervention being proposed. 
The interviewed patients rejected any attitude of paternalism from health service professionals and had a proactive approach towards the truth of their medical condition. Participants said they would prefer to have access to all the information about their illness even when this would involve facing difficult truths (bad news) because they believed this knowledge was essential for understanding their situation and making decisions. The following excerpts of three interviews are good examples:

"You can only decide what to do when you really know everything. I'm very glad they tell me everything."

"It's important to know what they're doing with you because that gives meaning to what's happening."

"I like to be told things, even if they're difficult to accept ... I like to know there's a good reason for what I'm going to do."

It was important for participants that the health care professionals kept them informed about how they were progressing during a course of treatment. The nursing staff were the ones they relied on most to answer questions and clarify doubts as we can see in the interviews conducted:

"It's the nurses who keep you informed from one day to the next."

“As I don't understand all the information, when I want to know what something in particular means I ask the nurse; I ask her what exactly it is I've signed."

"Of course I signed it; I read it and then I signed it. But afterwards, when the nurse came in, I asked her what it was all about".

"I asked the nurse because she's the one who spends most time with me. She was the one who helped me understand that I needed the treatment."

"I got more information from the nurses than from the doctors, especially about the chemo." 
When answering questions about the procedure in which they gave their consent, the participants described the importance of having a trusting relationship with a health professional that could help them understand what they were being given to sign.

"It's true the language is a bit technical. I was lucky because the doctor explained it to me in a way I could understand. The doctor even made me a sketch to show what exactly they would do and what kind of side effects it would have. Then they had me sign a form to let them go ahead with the operation, the treatment and the study."

It is very interesting to ascertain that if they trusted the health professional they were occasionally prepared to give their consent without having all the information they might be entitled to, especially information about technical details and medicines. A good example is the following explanation by a patient with breast cancer interviewee:

“"We're going to see if we can save your breast,' my doctor said, 'but I'm not completely sure what I'll find when I start operating and whatever it is, I'm not going to stop and sew you up so that I can ask you what you think before I go on; I mean, when I'm operating I've got to be able to do what I think is best in that moment.' So I signed the form to let him go ahead and do whatever was necessary during the operation without feeling his hands were tied. I didn't have an issue with that; I could see why he needed it and I trusted him completely. I never had any doubt. For the chemotherapy and radiotherapy I also had to sign forms, although they didn't tell me which drug they were going to use. I took it for granted that they knew how serious the problem was, in each person's case, and that they'd studied what would be best for me."

It is also very relevant to ascertain that, although the interviewee patients claim the need to be kept informed, it is not easy for them to obtain that information. The participants reported being given information that seemed to be geared to obtaining their consent but contained little or no explanation about the treatment or intervention being proposed; or they reported being given this information but having inadequate time to read and understand it. The following interview excerpt is a good example:

"The most important thing in the consent form should be the information; but that's not how it is really because you don't understand anything and they don't give you any time to understand it, either." 
The participants also reported that the side effects or possible risks that a course of treatment or intervention might have were, either not sufficiently explained or that they were not given adequate time to read and understand information about these. The following interview excerpts exemplify those ideas:

"When I had to sign the form for the stress test the doctor told me what I'd have to do in the test but he didn't say if there were any risks. He said I'd walk on this treadmill while they looked at my blood pressure with something on my arm; and that when I couldn't walk any more I should tell him and then he'd do whatever he had to."

"I can promise you they don't say everything they want to do. They say they're going to use something that can help them see things better and sometimes they give it to you in a shot [the participant is referring to a contrast agent] but that's all they tell you; and that's how it is wherever I've been and I've been in lots of places [the participant names three private clinics specializing in radiology]. They never tell you what they're doing anywhere [the participant names a number of state hospitals]. They don't tell you with the scans, either, not in the place I go every year [the participant names a private health centre]. They ask your permission to give you that shot because sometimes it has side effects, and if you're ready for that then you sign."

\section{Discussion}

The study confirms that in the Spanish health sector, as in the health systems of other countries 2728 , patients receive information and sign informed consent documents but need to be helped more effectively to understand the information about their medical condition. Their responses to the interviews confirm that patients with life-threatening illnesses are as concerned as other patients to have information that might help them participate in decision making, even when they do not directly ask to participate. ${ }^{29} 30$ The participants understood that health care professionals needed their consent to proceed with a treatment or an intervention and they expected to be given information that would help them understand why this had been deemed appropriate for their particular needs. In other words, they understood that completing a process of informed consent did not simply involve accepting or rejecting a professional proposal but was 
also an opportunity to understand that proposal. On the other hand, they reported that the information they received was null or scarce difficult to understand.

The participants' perception of the purpose of consent indicates that informed consent document may still be largely understood as a formality rather an ethical obligation, which in turn suggests that professional ethics in the Spanish health sector have some way to go. ${ }^{24}$ Our participants confirmed that the informed consent documents that they signed did not meet their ethical objectives. The professionals gave no importance to the reading of these documents, they did not explain the content in a way that could contextualize it for the patient in question, and they required the patient's consent almost immediately after a verbal explanation. ${ }^{31}$ This can indicate that for the health professionals the objective of the document is to demonstrate that the patient attests to the treatment or test.

The interviewed patients understood that their consent was necessary but their answers show that the consent process was applied as a matter of routine, a mere formality which the health professional knew had to be observed but which was given little time or explanation. The interviews indicate, therefore, that professionals in this sector are failing to observe two essential aspects of informed consent: the patients' right to comprehend their medical condition and their right to exercise their will. This failure and the fact that some participants also reported feeling coerced to sign the consent document suggest that, for some professionals, the objective of informed consent is to obtain the approval of the patient and their signature on the document. The study also bears this out, since participants report that the information given to them before they signed the document was primarily concerned with the specific technique or procedure the health professional wished to pursue and that the possible secondary or collateral effects were given less attention. ${ }^{32}$ This finding corroborated the study by Burns et al. which proposed that although patients reported that they were informed about their medical condition, they were not able to identify the risks of the treatments that they were consenting to. ${ }^{33}$ It corroborates as well the findings of another study on informed consent documents in nine Spanish hospitals that revealed that in over $90 \%$ of the documents given, the information on the side effects of the treatment being proposed 
was inadequate and that in more than $60 \%$ of the documents there was no clear explanation of the objectives of the treatment, intervention or test being proposed. ${ }^{34}$

Another salient factor can be observed when participants expressed the feeling that, by signing document, they were giving the health professional free reign to do what he or she wished; and that once this was the case, he or she did not even have to give the patient any more information after the new treatment had been started. For this reason patients also considered it important for the relationship between them and their doctors and nurses to be one of trust in which they were regularly informed about the progress they were making. The participants reported that the role of the nursing staff was especially important in keeping them informed about their health condition and clarifying their doubts. These data coincide with other studies that identify this role in nursing staff ${ }^{35}$ and confirm the ethical dimension of care that is geared towards helping a person to deal with their situation. ${ }^{12}$ In 1983 Davis and Aroskar had already described the optimum use of information and informed consent as one of the nursing profession's greatest ethical challenges ${ }^{36}$ and in 1986 in the first edition of her book Ethics in Nursing: the Caring Relationship Tschudin framed the ethics of nursing care in the relationship which the nurse establishes with the person receiving care. ${ }^{37}$ They did not discuss whether the information they received was from their doctors or nurses, but they all agreed it was important that the nurses helped them understand the information. The data show that the information about treatment, care, trials, etc. is difficult to understand if received all on just one informative occasion; and they also confirm that informed consent cannot be reasonably granted on the basis of a single information session but on a series of these. People understand decision making and feel involved in it when there is a sense of continuity in how they receive information and when the information is tailored to the moment they are experiencing in the overall care process, not when the information is received only occasionally, when health professionals need a patient's informed consent.

From the participants' answers, we can conclude that in the process by which informed consent is obtained, through the use of both verbal and written information, the attitude of professionals in the Spanish health sector continues to be paternalistic. Informed 
consent is still reduced to signing the document and, on certain occasions, may even cause the patient to feel a more acute sense of helplessness, given that he or she is aware of the seriousness of the information but is not given sufficient help to understand it. This underpins the notion that professionals' attitudes and behaviour are key factors in the application of informed consent; and it suggests that there is an important need for doctors and nurses to receive training in health ethics in this area of practice.

\footnotetext{
${ }^{1}$ Faden R and Beauchamp T. A history and theory of informed consent. New York: Oxford University Press, 1986.
}

2 Appelbaum PS. Assessment of patients' competence to consent to treatment. N Engl J Med. 2007; 357: 1834-1840.

${ }^{3}$ Moser A, Houtepen R, van der Bruggen $\mathrm{H}$, et al. Autonomous decision making and moral capacities. Nurs ethics 2009; 16: 203-218.

${ }^{4}$ Coulter A and Jenkinson C. European patients' views on the responsiveness of health systems and healthcare providers. The European Journal of Public Health 2005; 15: 355-360.

${ }^{5}$ Simón P. El consentimiento informado. Madrid: Triacastela, 2000.

${ }^{6}$ Schipper K, Widdershoven G and Abma T. Citizenship and autonomy in acquired brain injury. Nurs Ethics 2011; 18: 526-536.

${ }^{7}$ Lamont S, Jeon Y and Chiarella M. Health-care professionals' knowledge, attitudes and behaviours relating to patient capacity to consent to treatment: An integrative review. Nurs ethics 2013; 20: 684-707.

${ }^{8}$ Fry $\mathrm{S}$ and Johnstone M. Ethics in nursing practice: a guide to ethical decision-making. Geneva: International Council of Nurses, 2008.

${ }^{9}$ Forrester K and Griffiths D. Essentials of law for health professionals. Sydney: Elsevier (Mosby), 2005.

${ }^{10}$ Vall A and Rodríguez C. El derecho a la información del paciente: una aproximación legal y deontológica. Barcelona: BiD, 2008.

${ }^{11}$ National Commission for the Protection of Human Subjects of Biomedical and Behavioral Research, Department of Health, Education and Welfare. The Belmont Report. Washington, DC: United States Government Printing Office, 1978.

${ }^{12}$ Council of Europe. Convention for the Protection of Human Rights and Dignity of the 
Human Being with regard to the Application of Biology and Medicine. Oviedo: Council of Europe, 1997.

13 World Medical Association, et al. The International Code of Medical Ethics. Cologne: Medical ethics, journal of Forum for Medical Ethics Society, 1995. http://www.wma.net/en/30publications/10policies/c8/

${ }^{14}$ International Council of Nurses. The ICN code of ethics for nurses. Geneva: ICN, 2012.

15 Council of Nurses in Catalonia. Code of ethics (Codi d'ètica de les infermeres $i$ infermers de Catalunya). Barcelona: Consell de Col·legis d'Inferemres i Infermers de Catalunya, 2013.

${ }^{16}$ Ley General de Sanidad. Law 14/1986, of 25 April. Official Gazette of the Government of Spain (BOE), number 102(15/11/2002).

${ }^{17}$ Llei sobre els drets a la informació concernents a la salut i l'autonomia del pacient i la documentació clínica. Law 21/2000, of 29 December. Official Journal of the Government of Catalonia (DOGC), number 3303 (11/11/2001).

${ }^{18}$ Ley básica reguladora de la autonomía del paciente y de derechos y obligaciones en materia de información y documentación clínica. Law 41/2002, of 14 November. Official Gazette of the Government of Spain (BOE), number 274 (15/11/2002).

${ }^{19}$ Departamento de Sanidad y seguridad social. Guidelines on the application of informed consent. Barcelona: Departamento de Sanidad y Seguridad Social, 2003.

20 Simón P. Diez mitos en torno al consentimiento informado. An. Sist. Sanit. Navar. 2006; 29: 29-40.

${ }^{21}$ Cahill, J. Patient participation: a concept of analysis. J AdvNurs 1996; 24: 561-571.

${ }^{22}$ Millard L, Hallett C. and Luker K. Nurse-patient interaction and decision-making in care: patient involvement in community nursing $J$ AdvNurs 2006; 55: 142-150.

23 Thorne, S, Kirkham R and MacDonald-Emes, J. Focus on qualitative methods. Interpretive description: a noncategorical qualitative alternative for developing nursing knowledge. Research in nursing \& health 1997; 20: 169-177.

${ }^{24}$ Thorne, S, Kirkham R and O'Flynn-Magee, K. The analytic challenge in interpretive description. International journal of qualitative methods 2008; 3: 1-11.

${ }^{25}$ Knapik, M. The qualitative research interview: Participants' responsive participation in knowledge making. International Journal of Qualitative Methods 2008; 5: 77-93. 
${ }^{26}$ Jasper, M. Issues in phenomenology for researchers of nursing. Journal of advanced nursing 1994; 19.2: 309-314.

${ }^{27}$ Faghanipour S, Joolaee S and Sobhani M. Surgical informed consent in Iran-how much is it informed? Nurs Ethics 2014 May; 21: 314-22.

${ }^{28}$ Oosthuizen JC, Burns $\mathrm{P}$ and Timon C. The changing face of informed surgical consent. J LaryngolOtol 2012; 126: 236-9.

${ }^{29}$ Schattner A, Bronstein A and Jellin N. Information and shared decision-making are top patients' priorities. BMC HealthServ Res 2006; 28: 21.

30 Delgado A, López L, De Dios J, et al. Expectativas de los pacientes sobre la toma de decisiones ante diferentes problemas de salud. Gaceta Sanitaria 2010; 24: 66-71.

${ }^{31}$ McNutt L, Waltermaurer E, Bednarczyk R, et al. Are we misjudging how well informed consent forms are read? Journal of empirical research on human research ethics 2008; 3: 89-97.

32 Ziegler DK, Mosier MC, Buenaver M and Okuyemi K. How much information about adverse effects of medication do patients want from physicians? Arch Intern Med. 2001; 161:706-13.

${ }^{33}$ Burns $\mathrm{P}, \mathrm{Keogh}$ I and Timon C. Informed consent: a patient's perspective. $J$ LaryngolOtol 2005; 119: 19-22.

34 Calle J. Evaluación de la calidad formal de los documentos de consentimiento informado en 9 hospitales. Revista de Calidad Asistencial 2013; 28: 234-243.

35 Grace PJ and McLaughlin M. When consent isn't informed enough: What's the nurses' role when a patient has given consent but doesn't fully understand the risks? Am J Nurs. 2005; 105: 79-84.

${ }^{36}$ Davis A and Aroskar MA. Ethical dilemmas and nursing practice. Norwalk, CT: Appleton-Century-Crofts, 1983.

${ }^{37}$ Tschudin, V. Ethics in nursing: the caring relationship. Oxford: Heinemann, 1986. 